Moreover, the KCDC started reporting the situation from January 20 onward to provide accurate and real-time data. These reports included the number of confirmed cases and patients under investigation, history of confirmed cases, and prevention advice for the public. The number of the KCDC call center has been mentioned in almost every report, and Koreans were asked not to travel to China and Wuhan, to avoid public outdoor activities, to cough or sneeze safely, and to wear masks when visiting a health center. Besides, the guideline for management and screening get updated whenever needed; travel to Wuhan which was in the definition of suspected cases where changed to travel to china, and finally omitted. ${ }^{10}$

Altogether, the main goal of outbreak response in Korea was prevention of entrance of COVID-19 and at the same time, inhibition of the spread of the virus throughout the country. These goals were achieved through 3 main strategies: (1) containment and mitigation based on outbreak situation; (2) Risk communication to attract community participation; and (3) science-based and factdriven actions.

\section{Acknowledgments. None.}

Financial support. No financial support was provided relevant to this article.

Conflicts of interest. All authors report no conflicts of interest relevant to this article.

\section{References}

1. WHO director-general's opening remarks at the media briefing on COVID-19. World Health Organization website. https://www.who.int/dg/speeches/detail/ who-director-general-s-opening-remarks-at-the-media-briefing-on-covid19-11-march-2020. Published March 11, 2020. Accessed March 18, 2020.

2. Zhu N, Zhang D, Wang W, et al. A novel coronavirus from patients with pneumonia in China, 2019. N Engl J Med 2020;382:727-733.

3. Coronavirus (COVID-19) situation reports. World Health Organization website. https://www.who.int/emergencies/diseases/novel-coronavirus-2019/ situation-reports/. Updated April 3, 2020. Accessed April 3, 2020.

4. World Health Organization. A Framework for Global Outbreak Alert and Response. Geneva: World Health Organization; 2000.

5. Lee H-Y, Oh M-N, Park Y-S, Chu C, Son T-J. Public health crisis preparedness and response in Korea. Osong Public Health Res Perspect 2013;4:278-284.

6. Kim JY, Choe PG, Oh Y, et al. The first case of 2019 novel coronavirus pneumonia imported into Korea from Wuhan, China: implication for infection prevention and control measures. J Korean Med Sci 2020;35(5):e61.

7. Cho H-W, Chu C. How to manage a public health crisis and bioterrorism in Korea. Osong Public Health Res Perspect 2013;4:223-224.

8. Din MAU, Boppana LKT. An update on the 2019-nCoV outbreak. Am J Infect Control 2020. doi: 10.1016/j.ajic.2020.01.023.

9. Shim E, Tariq A, Choi W, Lee Y, Chowell G. Transmission potential of COVID-19 in South Korea. Int J Infect Dis 2020;93:339-344.

10. Press release: news room, 2020. Korean Centers for Disease Control and Prevention website. https://www.cdc.go.kr/board/board.es?mid=a304020 00000\&bid=0030. Accessed March 19, 2020.

\title{
The novel coronavirus (COVID-19) infection in Hangzhou: An experience to share
}

\author{
MengYuan Diao MDª, Sheng Zhang MDª, Dechang Chen $\mathrm{MD}^{2}$ and Wei Hu MD ${ }^{1}$ \\ ${ }^{1}$ Department of Critical Care Medicine, Affiliated Hangzhou First People's Hospital, Zhejiang University School of Medicine, Hangzhou, Zhejiang, China and \\ 2Department of Critical Care Medicine, Ruijin Hospital, Shanghai Jiao Tong University School of Medicine, Shanghai, China
}

To the Editor-Hangzhou, the capital of Zhejiang province in China, was confronted with the pandemic of a novel coronavirus (COVID-19) that originated in Wuhan, Hubei province. ${ }^{1}$ According to the Health Commission of Zhejiang Province, ${ }^{2}$ 6 cases were first reported on January 19, 2020, and the cumulative cases reached 169 as of February 20, 2020. The situation in Hangzhou was once rather severe-it was the top-ranking city with respect to the number of confirmed cases in Zhejiang province at the beginning of the epidemic. Since the Hangzhou government took rigorous measures to contain the epidemic, positive trends have been observed. The daily number of newly confirmed cases has sharply decreased within the last week, and only 1 case was confirmed from February 17 to 20. Similarly, Hangzhou reported no deaths in its administrative region. We used a regression of logincidence over time model $^{3}$ to provide a fitted trajectory for the actual daily incidence to verify the control effect. As shown in Figure 1, the optimal splitting point, defined as the peak number

Author for correspondence: Dechang Chen, E-mail: chendechangsh@hotmail.com. Or Wei Hu, E-mail: paolohu929@zju.edu.cn

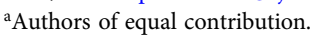

Cite this article: Diao MY, et al. (2020). The novel coronavirus (COVID-19) infection in Hangzhou: An experience to share. Infection Control \& Hospital Epidemiology, 41: 874-875, https://doi.org/10.1017/ice.2020.62 of daily new cases simulated by the model, occurred on January 25. This peak occurred about a week after launching the highest level of emergency public health alert and response in Hangzhou, which indicates that the prevention and control measures may have been effective.

Overall, 6 major measures were taken to control and prevent the spread of COVID-19 in Hangzhou. First, aware of the seriousness of the situation, on January 23, 2020, the Zhejiang province authorities launched a Level I Public Health Incident Alert, the highest level of emergency public health alert and response in the nation's public health management system. As the top level of China's public health alert system, this measure imposed the maximal limit on movement by people. Second, further action was taken on February 3, 2020, when most districts of Hangzhou announced that every community would be kept under closed management and that only 1 family member was allowed to leave the house to buy daily living supplies every 2 days. Third, "noncontact delivery," a new delivery method, was adopted by many express delivery companies to reduce contagion risk. Fourth, to reduce the concentration of personnel to avoid the risk of cross infection, online working and network teaching were encouraged for workers and students, respectively. These measures were supported by mobile technology companies. Fifth, 
Fig. 1. The impact of a public emergency health alert on the daily incidence of COVID-19 infection in Hangzhou. The fitted trajectory shows the probable daily incidence with $95 \%$ confidence interval derived from existing data using a log-incidence over time regression model. The split point is the optimal date to split the epicurve into two phases, which best fits the model. Other interventions include restricted movement outside the home, noncontact delivery, online work and teaching, etc.

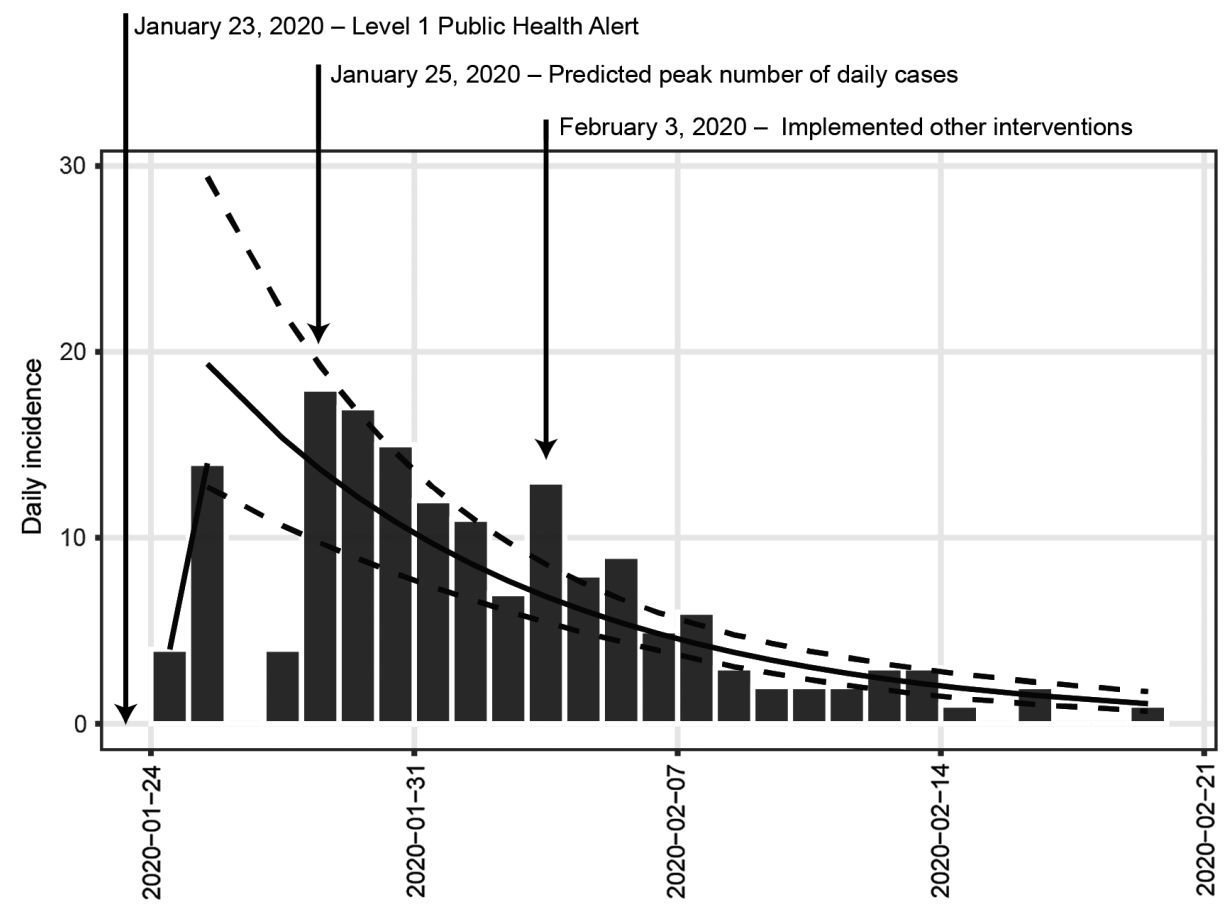

to meet the need to resume production and curb the transmission of the virus as far as possible, Hangzhou arranged chartered transportation to help numbers of migrants return to their work places. Lastly, in cooperation with Alipay, Hangzhou adopted the health quick-response (QR) code system on February 11, 2020, which were designated by green, yellow, or red. People who wanted to get into Hangzhou needed to submit their travel history and health information online in advance. Residents with a green code indicated they had a low current risk of being infected, while residents with yellow or red codes were quarantined for 7 or 14 days and were required to report their health condition daily to exclude infection before the code was changed to green. This health surveillance system has now been applied in most cities in Zhejiang province and will be promoted in other provinces.

Although the effect of prevention and control measures is evident, Hangzhou continues to face huge challenges owing to its large immigrant population. However, this city has already learned much from this epidemic, and we hope that some of our experiences will assist others in their regions.

Acknowledgments. None.

Financial support. No financial support was provided relevant to this article.

Conflicts of interest. All authors report no conflicts of interest relevant to this article.

\section{References}

1. Huang C, Wang Y, Li X, et al. Clinical features of patients infected with 2019 novel coronavirus in Wuhan, China. Lancet 2020;395:497-506.

2. Epidemic situation of new coronavirus pneumonia in Zhejiang province, 2020. Health Commission of Zhejiang Province website. http://www.zjwjw. gov.cn/art/2020/2/21/art_1202194_41958075.html. Published 2020. Accessed February 21, 2020.

3. Kamvar Z N, Cai J, Pulliam J, Schumacher J, Jombart T. Epidemic curves made easy using the R package incidence. F1000Res 2019;8:139.

\title{
COVID-19 positive test result from a private hospital laboratory: Neglecting to report and problems with national infection control
}

\author{
Won Sriwijiatalai ${ }^{1}$ and Viroj Wiwanitkit ${ }^{2,3}$ \\ ${ }^{1}$ TWS Medical Center, Bangkok, Thailand, ${ }^{2}$ Dr DY Patil University, Pune, India and ${ }^{3}$ Hainan Medical University, Haikou, China
}

Author for correspondence: Won Sriwijiatalai, E-mail: wonsriwi@gmail.com

Cite this article: Sriwijiatalai W and Wiwanitkit V. (2020). COVID-19 positive test result from a private hospital laboratory: Neglecting to report and problems with national infection control. Infection Control \& Hospital Epidemiology, 41: 875-876, https://doi.org/10.1017/ice.2020.93
To the Editor-The new coronavirus disease (COVID-19) is a new global public health problem. It already affects more than 140 countries around the world. Thailand is the second country in the timeline of disease pandemic. ${ }^{1}$ The infection has occurred 